\title{
Effect of body weight at first mating on reproductive performance of rabbit does
}

*Ayo-Ajasa, O. Y., Egbeyale, L.T., Adewole, F. A., Ekunseitan, D. A. and Babalola, O. A. Department of Animal Production and Health,

Federal University of Agriculture, Abeokuta

Corresponding author: olapejuyemisi@yahoo.com;

Abstract

ayo-ajasaoy@funaab.edu.ng

Eighteen mature nulliparous rabbit does with initial body weight between 1600g-2500g were used to evaluate the effect of body weight at first mating on reproductive performance of rabbit does. These rabbits were assigned into three treatments, with T1, T2 and T3 weighing (1600-1900), (1901-2200) and (2201-2500) respectively. The study lasted for 5weeks. The does were mated with buck at ratio 1:3. The reproductive parameters evaluated were number of does that kindled, litter size at birth, breeding efficiency, litter size at weaning, preweaning loss. All data collected were subjected to descriptive statistical representation. The highest number of kindled does was 5 in T2 and T3; T1 had the lowest number (3). Breeding efficiency of $83.33 \%$ was recorded in $T 1$ and T2 while T3 had 50.00\%. T3 had highest average birth weight (49.51g) and T2 had the least (41.51g); litter size at birth and weaning ranged from 18 -28kits and 15-24kits, respectively. T2 does recorded highest value in both parameters, 73 does recorded same value (28kits) for litter size at birth. Highest preweaning loss of 7 kits was recorded from does in T3 while T1 and T2 recorded 4 kits. It was therefore concluded that does with weight range $1901 \mathrm{~g}-2200 \mathrm{~g}$ had better reproductive performance with highest breeding efficiency and lower pre-weaning loss.

Keywords: Rabbit does, body weight, reproductive performance

\section{Introduction}

Rabbit farming is becoming more attractive to many animal breeders due to its high fecundity, high mothering ability, adaptability to a wide range of conditions, high genetic variability, high roughage utilization and low cost of production (Das and Yadav, 2007). Reproductive performance is the main factor which assures high productivity on rabbit farms. This requires that the management practices take into account the physiology and behaviour of the animals. For great profit a special attention must be focused on these traits, so studying factors that directly affect them are so important and must be taken into consideration during breeding of any productive species. Rabbit does experience a severe energy deficit during the first lactation; they tend to lose weight after their first litter until the kindling of second litter. This is due to the high energy needs of foetal growth combined with the drop in the feed intake during the last 10 days of gestation. This weight loss by first litter doe accounts for a drop in reproductive performance and a high replacement rate of young does (Rommers et al., 2002). Likewise does are often fed to appetite during rearing, and first mating is recommended at approximately 75 to $80 \%$ of mature body weight (Lebas et al., 1986). In modern management, young does are not mated at a fixed body weight but at a fixed age. Under ad libitum feeding conditions during rearing, heavy does can develop according to their growth potential, and body weight differences at first mating will be substantial. At the same age, heavy does can benefit from the extra amount of body 


\section{Effect of body weight at first mating on reproductive performance of rabbit does}

weight at the end of rearing to withstand the energy deficit during first lactation. Rommers et al. (2002) reported that body weight did affect productive performance in the first parity. Although heavy does were heavier at first mating and remained heavier throughout the reproductive period, they followed a similar body weight curve after weaning the first litter as small and medium does. Hence, this study evaluated the effect of body weight at first mating on reproductive performance of rabbit does.

\section{Materials and methods Experimental site}

The experiment was carried out at the Rabbitry Unit, Teaching and Research Farm Development (TREFAD), College of Animal Science and Livestock Production Farm, Federal University of Agriculture Abeokuta. It falls within the rainforest vegetation zone of South West Nigeria on the latitude 7?S 13'49.66' $\mathrm{N}$ and longitude 3? 26'11.98 E 76m above sea level (Google earth, 2018). The climate is tropical humid with a mean annual rainfall of $1037 \mathrm{~mm}$, a temperature of 43 ?C and a relative humidity of $82 \%$.

Experimental animals and management A total of 18 mature nulliparous rabbit does and 6 bucks (mixed breeds) were purchased from a reputable farm in Abeokuta, Ogun State. The does were distributed into three treatments, of six does per treatment. Each treatment was further subdivided into six replicates consisting of one does per replicate. On the arrival of the rabbits, they were given feed and water containing antistress (Maxiyield). The rabbits were allowed to acclimatize with the environment for one week (7 days) before the commencement of the experiment. The hutches and equipment that were used were thoroughly washed and disinfected with morigard before stocking the rabbits. The rabbits were kept in hutches equipped with concrete pots of feeders and drinkers. They were supplied with clean water in concrete drinkers and fed on commercial diet (Table 1) in concrete feeders and were also given Tridax procumbens twice a week. The droppings were swept off every day, and the rabbit were observed for any sign of illness.

Table 1: Nutrient composition of the commercial feed (As declared)

\begin{tabular}{ll}
\hline Parameter & Value \\
\hline Crude Protein (\%) & 16.00 \\
Fats and Oil (\%) & 5.00 \\
Crude Fibre (\%) & 7.00 \\
Calcium (\%) & 1.60 \\
Available Phosphorus $\quad(\%)$ & 0.45 \\
Lysine (\%) & 0.75 \\
Methionine (\%) & 0.36 \\
Salt (\%) & 0.30 \\
Metabolizable Energy (kcal/kg) & 2450 \\
\hline
\end{tabular}

\section{Experimental procedure}

The does were mated with a mating ratio of $1: 3$. The doe were hand mated in the morning and evening; the bucks were allowed to ride 3-4 times before the does were withdrawn. Pregnancy test was carried out on the does by palpating at the $14^{\text {th }}$ and $20^{\text {th }}$ day after mating. Clean and well disinfected kindling boxes were provided for the does to make nest of fur in preparation for birth. The rabbits were weighed on the day of kindling and subsequent weighing was done every week. Gloves were used for handling the kits.

\section{Experimental treatments}

Treatment 1: Does weighing between 1600 
$-1900 \mathrm{~g}$

Treatment 2: Does weighing between 1900 $-2200 \mathrm{~g}$

Treatment 3: Does weighing between 2200 $-2500 \mathrm{~g}$

\section{Data collection}

Data were collected on breeding efficiency (percentage of kindled does), litter size at birth (number of kits per doe at birth), litter size at weaning (number of kits per doe at weaning), average birth weight (weight of kits of a doe at birth divide by the total number of the kits), pre weaning loss (number of kits that died before weaning) and gestation length (difference between conception date and kindling date).

Statistical analysis

All data obtained was analysed through the use of descriptive statistical tools.

\section{Results}

The effect of body weight at first mating on reproductive performance of rabbit does are presented in Figure 1 and Figure 2 below. Figure 1 shows the effect of body weight at first mating on number of kindled does, gestation length and breeding efficiency. The number of does that kindled ranges from 3 to 5 with the does in T2 and T3 recording the highest breeding efficiency $(83.33 \%)$ and does in $\mathrm{T} 1$ recording the lowest breeding efficiency $(50.00 \%)$, respectively. The gestation length is longer in does in $\mathrm{T} 1$ and $\mathrm{T} 3$ with duration of 32 days while the does in $\mathrm{T} 2$ recorded shorter with duration of 31days. The effect of body weight on average birth weight, litter size at birth, litter size at weaning and pre-weaning loss is presented in figure 2 . The average birth weight of the kits ranged from $41.57 \mathrm{~g}$ to $49.57 \mathrm{~g}$. Kits from does in T3 had highest $(49.57 \mathrm{~g})$ while kits from T2 recorded the least $(41.57 \mathrm{~g})$ average birth weight. Litter size at birth and weaning ranged from 18 to 28 and 15 to 24 , respectively with the does from T2 recording the highest values for both parameters while does from T3 also recorded the same value (28) for litter size at birth. The highest pre-weaning loss of 7 was recorded from does in $\mathrm{T} 3$ while does in $\mathrm{T} 1$ and $\mathrm{T} 2$ recorded same pre weaning loss of 4 kits.

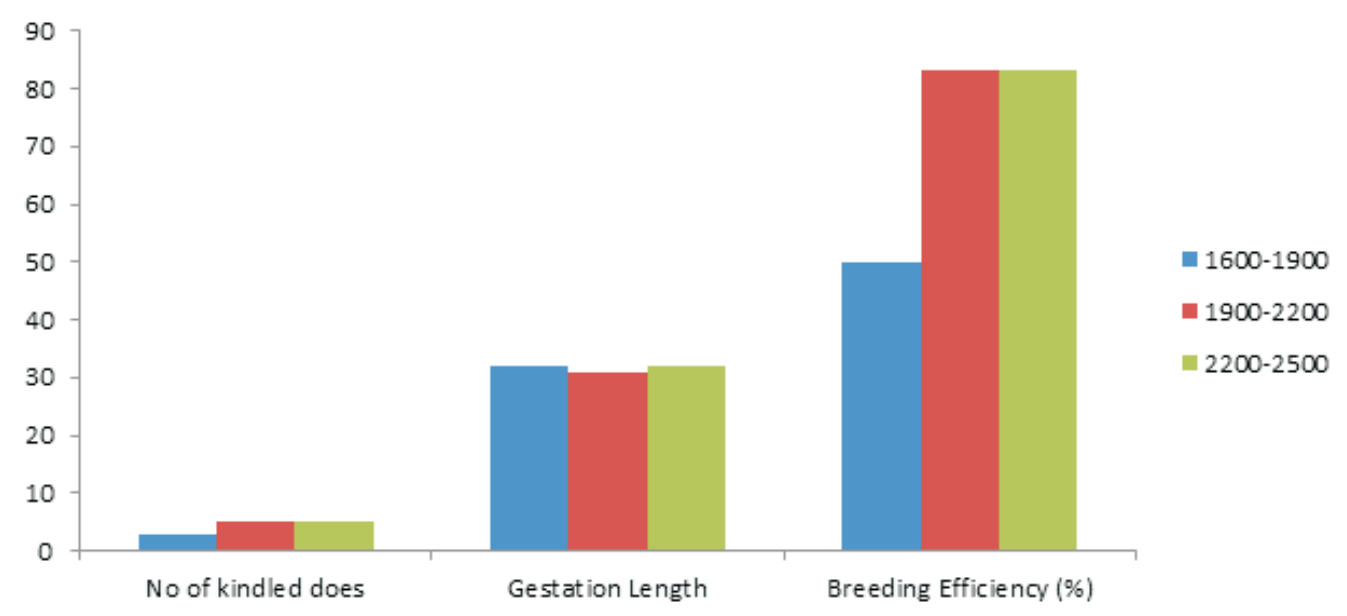

Figure 1: Effect of body weight at first mating on number of kindled does, gestation length and breeding efficiency 


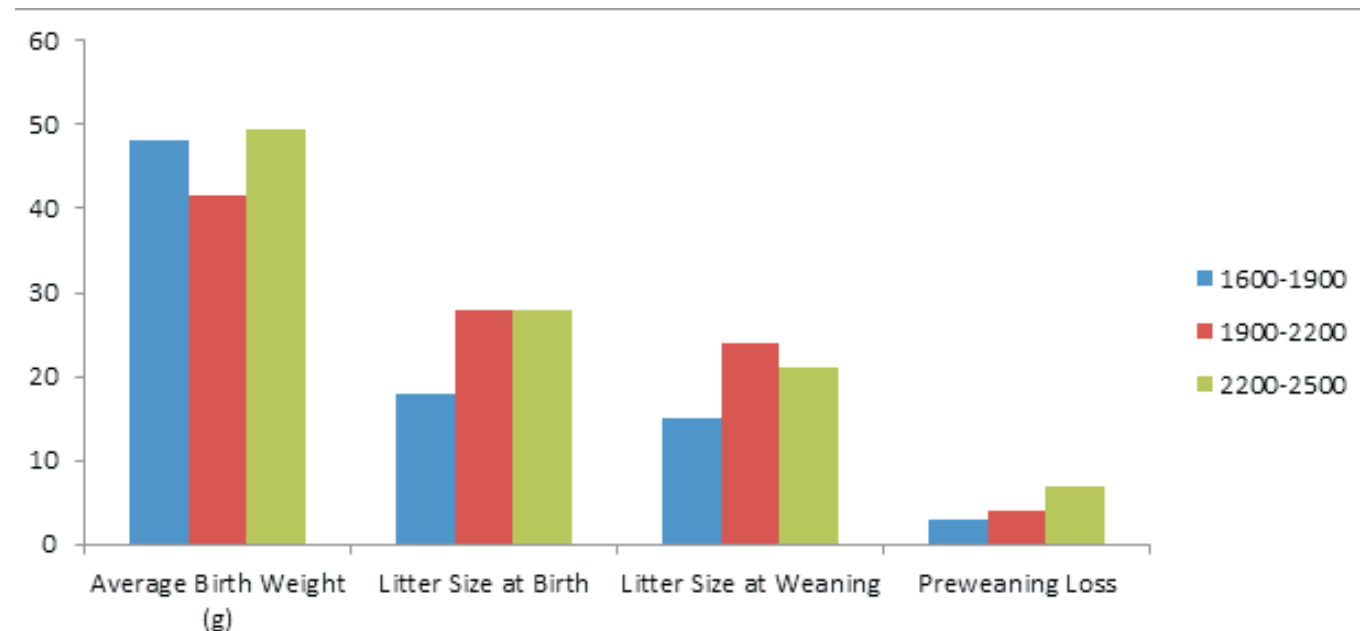

Figure 2: the effect of body weight on average birth weight, litter size at birth, litter size at weaning and pre-weaning loss

\section{Discussion}

The result obtained from does with weight between 1600-1900g having lower breeding efficiency, litter size at birth and litter size at weaning could be as a result of small body size and insufficient body reserve with a possible reduction in the milk production of the does and hence resulting in lower reproductive performance. This result is in line with the report of Szendrö et al. (2002) that the insemination of animals with lower body weight has been related to lower fertility and smaller litter size at first parturition (Rommers et al., 2001; 2002). Rabbit does are susceptible to a severe energy deficit during first lactation (Xiccato, 1996), resulting in a decreased reproductive performance. Heavy does are more matured and have more body reserves (protein and fat tissue) which enable them to better resist energy deficit during first lactation, resulting in a better performance (Rommers et al., 2004). Gestation duration ranged from 31 to 32 days gestation length in rabbit respectively is fixed and only varies within a very narrow gap as observed in this study; similar observation was made by Ajayi et al. (2005). The highest numerical value recorded for litter size at birth and weaning by does weighing between 1900 and $2200 \mathrm{~g}$ shows that increased body weight improved reproductive performance at first parity. According to Inglis (1980), litter size and birth weight vary depending on the breed and size of the dam. Factors that increase litter size include the age at which the does are served and the optimum weight at service, which is an index of breed (Hafez and Hafez, 2000).

\section{Conclusion}

The study concluded that does with weight range $1901 \mathrm{~g}-2200 \mathrm{~g}$ had better reproductive performance with highest breeding efficiency and lower pre-weaning loss.

\section{References}

Ajayi, F. O., Balogun, O. O., Ovuru, S. S. and Mgbere, O. O. 2005. Reproductive performance of rabbit fed maize milling waste based diet. African Journal of Biotechnology, 4: 439-443.

Das, S. K. and Yadav, B. P. S. 2007. Effect of mating system, parity and breed on the reproductive performance of 
young rabbit does. Journal of Animal Science. 79: 1973-1982.

Hafez, E. S. E. and Hafez, B. 2000. Reproductive cycles.In E.S.E. Hafez and B. Hafez (eds). Reproduction in farm Animal. 7th Edition. Balliene Tindal, London, Great Britain.

Inglis, J. K. 1980. Introduction to laboratory animal science and Technology, Perganon press, Oxford, 3-4.

Lebas, F., Codert, P., Rouvier, R. and Rochambeau, H. 1986. The rabbit: Husbandry and Healthy. FAO. Animal Production and Health Series, no.21.202 Pp.

Rommers, J. M., Meijerhof, J. P., Noordhuizen, T. M. and. Kemp, B. 2001. Effect of different feeding levels during rearing and age of first insemination on body develoment, body composition, and puberty characteristics of rabbit does. World Rabbit Science. 9:101.-108.
Rommers, J. M., Meijerhof, J. P., Noordhuizen. T. M. and Kemp. B. 2002. Relationships between body weight at first mating and subsequent body development, feed intake reproductive performance of rabbit doe. Journal of Animal Science 80:2036-2042.

Rommers, J. M., Meijerhof, J. P., Noordhuizen, T. M. and Kemp, B. 2004. Effect of feeding program during rearing and age at first insemination on performance during subsequent reproduction in young does. Reproduction Nutrition Den., 44; 321-332.

Szendro, Z. S., Gyarmati, T., Maertens, L., Biro-Nemeth, E., Radnai, I., Milisits, G. and Maotics, Z. S. 2002. Effect of nursing by two does on the performance of suckling and growing rabbits. Animal Science, 74; 117-125.

Xiccato, G. 1996. Nutrition of lactating does. In: 6th World Rabbit Congress, 1:29-47.

Received: $14^{\text {th }}$ June, 2019

Accepted: $18^{\text {th }}$ December, 2019 